\title{
In vitro Preparation and Evaluation of
}

\section{Sustained-Release Microcapsules of Salvianolic Acid}

\author{
Yun-Hong Wang' \\ Tong $\mathrm{Qu}^{2}$ \\ Xue-Lian Wang ${ }^{3}$ \\ Rong-Ping Yang ${ }^{3}$
}

'Chongqing Academy of Chinese Materia Medica, Chongqing, 400065, People's Republic of China; ${ }^{2}$ Shaanxi University of Chinese Medicine, Xianyang, 7I 2046, People's Republic of China; ${ }^{3}$ Department of Pharmacy College, Southwest University, Chongqing, 4007/5, People's Republic of China
Correspondence: Rong-Ping Yang Department of Pharmacy College, Southwest University, No. 2 of Tiansheng Street, Beibei District, Chongqing, 4007I5, People's Republic of China Tel +86 023-6825I 225

Fax +86 023-6825I225

Email yangrongpingII19@163.com
Objective: This study aims to investigate the prep ation of sustan $-r$ ase microcapsules of salvianolic acid.

Methods: The stability of salvianolic aci micro ales was and the time of action was prolonged in the present stur this was pro red ang the spray-drying method, with chitosan as the carrier. In the epara n process, orescription and process were optimized by L9 (34) using an orthogonal desis with yield and drug loading as indexes, in order to obtain optimum cor mons.

Results: The optimal pr ess and pre ription for the preparation of salvianolic acid microcapsules were found be as foll $\mathrm{s}$ : mass concentration of chitosan, $1.5 \%$; mass ratio of salvianolic acid to $\mathrm{C}$ an, $1: 3$ hlet air temperature, $190^{\circ} \mathrm{C}$; and peristaltic pump speed, $300 \mathrm{~mL}$. surface or the microcapsules was round, the drug loading was $25.99 \% \pm 2.14 \%$, e yie $\quad 51.88 \% \pm 2.84 \%$, the entrapment efficiency was $86.21 \% \pm$ $2.89 \%$ the ave particle size was $105.6 \pm 2.56 \mathrm{~nm}$. The microcapsules in vitro had cert susta ed rele characteristics. The internally fitted first-order release model equawas lo $2 \mathrm{O}=-\mathrm{0} 236 \mathrm{t}+4.5917, \mathrm{r}=0.920$. In addition, the results of differential scan calorimetry show that the properties of salvianolic acid were not changed by the microca yles.

Conclusic Sustained-release microcapsules of salvianolic acid can be successfully prered by adopting marine polysaccharide as a carrier.

Ke, cords: salvianolic acid sustained-release microcapsule, marine polysaccharides, chitosan, Salvia miltiorrhiza, salvianolic acid B

\section{Introduction}

The dry root and rhizome ${ }^{1-3}$ of the plant Salvia miltiorrhiza Bge (of the Labiatae family) are often used to treat cardiovascular and cerebrovascular diseases. ${ }^{2,4,5}$ Modern pharmacological research has revealed that salvianolic acid B is one of the effective components of S. miltiorrhiza. This is a tetrameric caffeic acid compound, which is condensed by two-molecule tanshinol and one-molecule prolithospermic acid. However, its chemical properties are very unstable and easily degraded. ${ }^{6}$ Microcapsules are tiny capsules that encapsulate solid or liquid drugs, along with excipients that can improve the stability of the drugs and mask their unpleasant smells. ${ }^{7}$ As stable carriers, microcapsules are widely used in the preparation of chemical drugs; however, they are rarely used in traditional Chinese medicine. The purpose of this study was to apply microencapsulation technology to certain main 
components of traditional Chinese medicine, so as to realize their potential as patent medicines. To this end, in the present study, salvianolic acid B was prepared into microcapsules using marine polysaccharide as a carrier.

\section{Methods}

\section{Materials and Instruments}

All materials used-salvianolic acid B control (National Institute for the Control of Pharmaceutical and Biological Products, Batch No. 110817-200605), salvianolic acid (salvianolic acid B: 58\%, Xi'an Honson Biotechnology Co., Ltd., Batch no. 090927), chitosan (degree of deacetylation $\geq 95 \%$, viscosity $<60 \mathrm{cp}$, Shandong AK Biotech Co., Ltd., Batch no. 090926), hydrochloric acid (Chongqing Chuandong Chemical [Group] Co., Ltd., Chemical Reagent Factory), and other reagents - were analytically pure.

The instruments used were as follows: Agilent 1200SL RRLC (Agilent, USA), SD-1500 small spray dryer (Shanghai Wodi Technology Co., Ltd.), H-7500 transmission electron microscope (Japan Hitachi), S-3000N scanning electron microscope (Japan Hitachi), Zetasizer Nano ZS90 nanometer particle size and zeta potential analyzer (Malvern, UK), Spectrum One infrared spectrometer (Perkin-Elmer, USA) STA-449C differential scanning calorimeter (Netzso Germany), AW-200 electronic balance (Shimadzu, Japan), and ZRS-8G intelligent dissolution tester (Tianji Wireless Power Plant).

\section{Preparation of Salvianolic cid Microcapsules}

Chitosan was precisely we hed and di lved with 0.1 $\mathrm{moL} \cdot \mathrm{L}^{-1}$ of hydrochlor acid to prepare svutions with different mass concer tions and these were placed in standby. The salyianolic was di olved into the chitosan solution $\mathrm{d}$ pr ared $\mathrm{t}^{1}$ solution, and sprayed according a certa nroportion. This was evenly stirred for spray dry er stanaing and removing the bubbles.

\section{Evaluation of Lrug Loading}

Approximately $60 \mathrm{mg}$ of microcapsule powder was precisely weighed and placed in a $25-\mathrm{mL}$ flask. Hydrochloric acid was added for dissolution and constant volume. After ultrasound, the liquid was shaken, and $1.0 \mathrm{~mL}$ was transferred into a flask and diluted to scale with $0.1 \mathrm{~mol} \cdot \mathrm{L}^{-1}$ of hydrochloric acid solution. Then, peak area A was determined. The drug mass concentration was calculated according to the standard curve equation, and drug loading was calculated according to the following formula: drug loading $=$ drug content in microcapsules/total mass of microspheres $\times 100 \%$.

\section{Determination of Yield}

The microcapsules in the receiving flask were collected using a spray dryer and weighed. The percentage of feed volume of the microcapsules, ie, the yield, was calculated. The calculation formula was yield $=$ obtained microcapsule quality/total feed volume $\times 100 \%$.

\section{Preparation Method}

Specificity test. Controls were pre $\mathrm{N}_{\mathrm{N}}$ ed as follo s: salvianolic acid B controls 0.00771 wer accurately weighed, dissolved y $15 \%$ thanol, d diluted to $25 \mathrm{~mL}$ to obtain $\mathrm{xe}$ oduct. Por the salvianolic acid extract sol on, salvic lic a d extract of 0.02065 $\mathrm{g}$ was accur ay ighed; aga this was dissolved with $75 \%$ ethanol and dh to $25 \mathrm{~mL}$ to obtain the final prody For the blank lution, $0.02589 \mathrm{~g}$ of chitosan was recisely weighed and dissolved in water, and diluted to $2 \mathrm{~mL}$ to obta the final product. The sample solution was $p$ ared $b$ precisely weighing $0.06081 \mathrm{~g}$ of microcules, wnich were dispersed with a small amount of $\mathrm{a}^{1}$ olum thyl alcohol; $0.2 \mathrm{moL} / \mathrm{L}$ of hydrochloric acid was added to dissolve and dilute this to $25 \mathrm{~mL}$.

Sample assay methods. From each of the abovementioned solutions, $20 \mu \mathrm{L}$ was injected into the liquid chromatograph for determination.

\section{Results}

\section{Sample Specificity Chromatogram}

As stated above, $20 \mu \mathrm{L}$ of the sample solution was injected into the liquid chromatograph. The results, presented in Figure 1, reveal that chitosan was completely separated from the main drug and had no interference with the determination of the drug. Furthermore, this was strongly specific.

\section{Establishment of Standard Curves}

Next, $1.59 \mathrm{mg}$ of salvianolic acid B control was accurately weighed and dissolved with $75 \%$ methanol solution to a constant volume of $25 \mathrm{~mL}$, in order to prepare a solution of $63.60 \mu \mathrm{g} \cdot \mathrm{mL}^{-1}$. Each $0.25,0.50,0.75,1.00$, 1.50 , and $2.00 \mathrm{~mL}$ of solution was taken into a $10-\mathrm{mL}$ volumetric flask, and $75 \%$ methanol solution was used to maintain a constant volume. The above series of standard 
Control
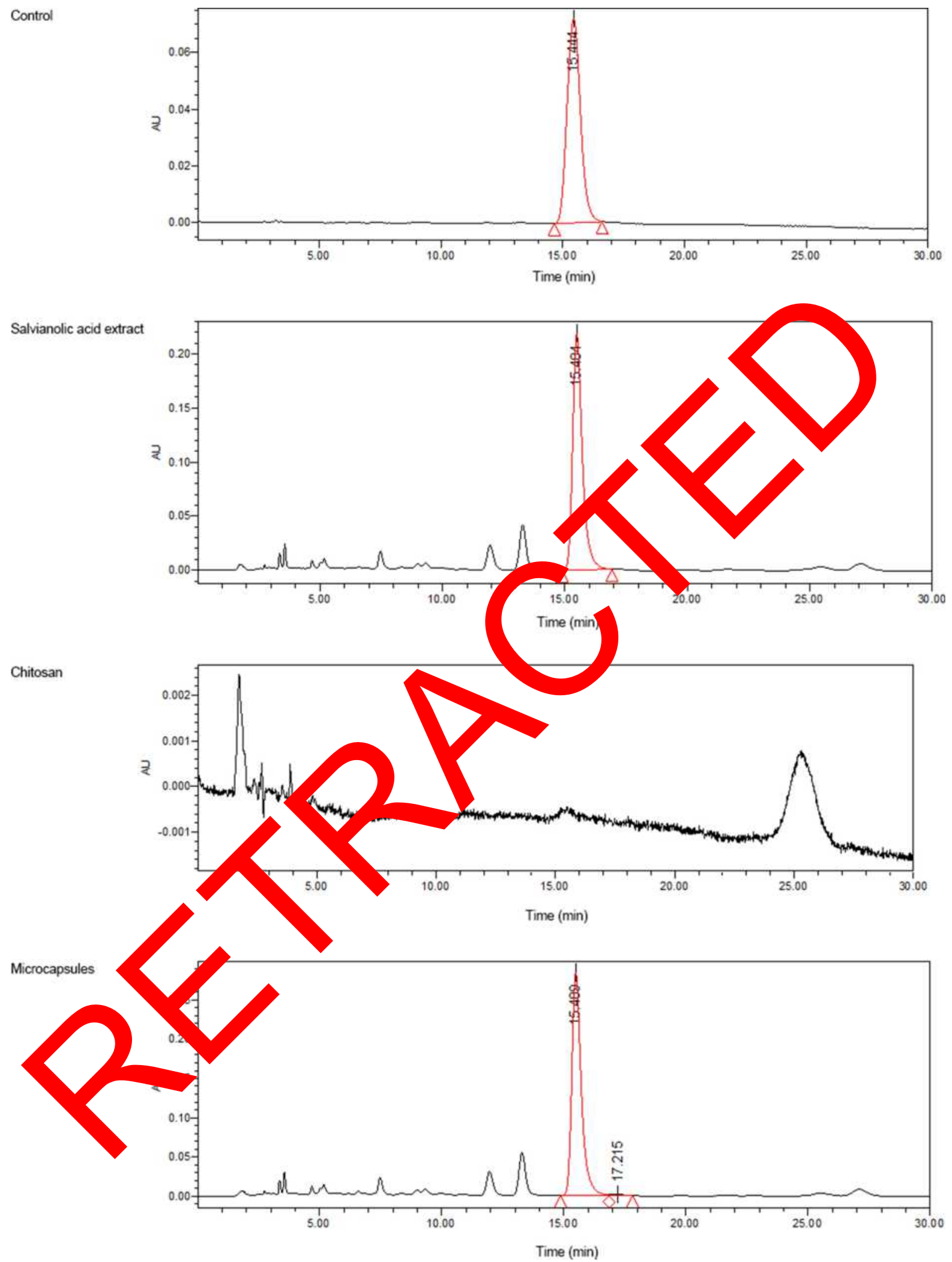

Figure I Specificity of the chromatogram. 
solutions was filtered via a $0.45 \mu \mathrm{m}$ millipore filter. This was tested based on chromatographic conditions in Sample Specificity Chromatogram. The sample injection was 20 $\mu \mathrm{L}$. Peak area A was measured as the longitudinal coordinate, while linear regression was conducted for the concentration according to the regression equation: $\mathrm{A}=1.765$ $6 \mathrm{X}-0.2306, \mathrm{r}^{2}=0.999 .8$. The results show that salvianolic acid B has a good linear relationship between 1.59 and $12.72 \mu \mathrm{g} \cdot \mathrm{mL}^{-1}$.

\section{Precision Test and Recovery Test}

The prepared mass concentrations were 1.59, 6.36, and $12.72 \mu \mathrm{g} \cdot \mathrm{mL}^{-1}$. The salvianolic acid B control solution was measured three times a day. The relative standard deviation (RSD) was calculated as $1.73 \%, 2.16 \%$, and $0.93 \%$, respectively, within the day. Measurements were taken at day 1,2, and 3, and the calculated RSD was $0.93 \%, 1.45 \%$, and $1.96 \%$, respectively, within the day.

Quantities of 1.12, 2.23, and $3.03 \mathrm{mg}$ of salvianolic acid B controls were accurately weighed, and blank microcapsules were added according to the prescription dosage. These quantities were dissolved with 0.1 $\mathrm{mol} \cdot \mathrm{L}^{-1}$ of hydrochloric acid to prepare mass concent

\section{Single-Factor Test for the Selection of the Spray Drying Process}

A series of microcapsules was prepared according to the method in Preparation of Salvianolic Acid Microcapsules, based on drug-to-chitosan ratios of 1:1, 1:2, 1:3, and 1:4. The results reveal that when the ratio of drug to chitosan was 1:4, the drug loading and yield of the microcapsules were low, because the ratio of drug to chitosan was too small. When the ratio of drug to chitosan was $1: 1$, the salvianolic acid extract could not be completely dissolved in the chitosan. Therefore, the ag-to itosan ratio should be between 1:2 and 1:3 ble 1).

A series of microcapsule was pared usi chitosan mass concentrations of $0.5^{\circ}, 0.8 \%, 1.0 \%$ and $\% \%$, according to the method Prepar on of Suvianolic Acid Microcapsules. Th xpen al resul show that the mass concentration hitosan sho d/ controlled within the range of 0.8 to 1. This is bevause when the viscosity of the chito golution is high, the nozzle can easily become bloc d, preventing the spray process from being carried out nor ally; howevs when the concentration is too low $(0.5 \%$ or le the micr apsule powder is mainly deposited in the chunt flas arting in a lower yield (Table 2). tions of $1.59,6.36$, and $12.72 \mu \mathrm{g} \cdot \mathrm{mL}^{-1}$, respectively, i order to test peak area A. The results indicatethat the average recovery rate was $99.62 \%, 10.36 \%$, and $99.31 \%$, respectively. dlvianolic Acid Microcapsules, a series of microcapsules vas prepared with peristaltic pump velocities of 300,400 , 00,600 , and $700 \mathrm{~mL} \cdot \mathrm{h}^{-1}$. During the experiment, it was

Table I Drug Loading Caused by ifferen, patio of Dru. to Chitosan

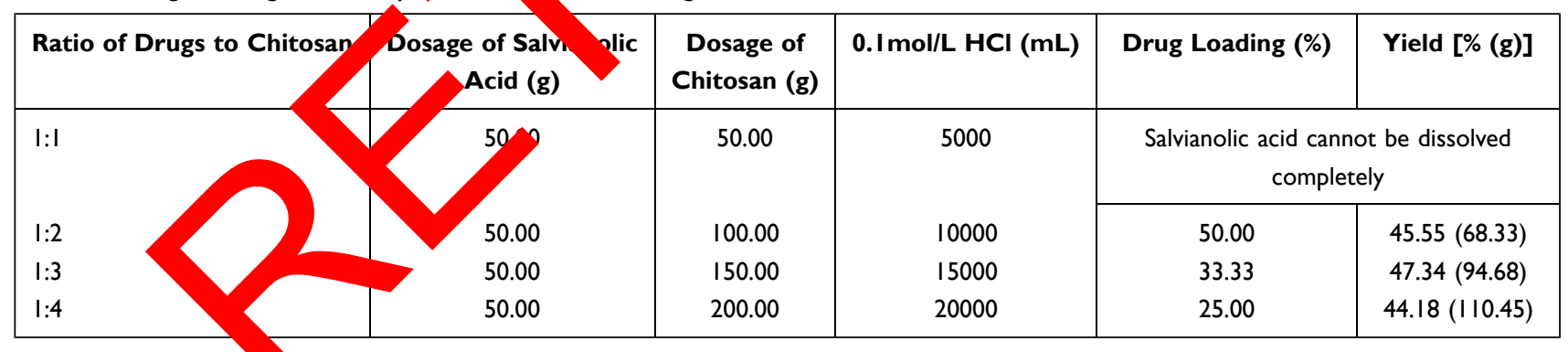

Table 2 Drug Loading Caused by Different Concentration of Chitosan

\begin{tabular}{|l|c|c|c|c|c|}
\hline Concentration of Chitosan (\%) & $\begin{array}{c}\text { Dosage of Salvianolic } \\
\text { Acid (g) }\end{array}$ & $\begin{array}{c}\text { Dosage of } \\
\text { Chitosan (g) }\end{array}$ & 0.I mol/L HCl (mL) & Drug Loading (\%) & Yield [\% (g)] \\
\hline 0.5 & 50.00 & 150.00 & 30000 & 33.33 & $31.41(62.81)$ \\
0.8 & 50.00 & 150.00 & 18750 & 33.33 & $41.16(82.32)$ \\
1.0 & 50.00 & 150.00 & 15000 & 33.33 & $47.34(94.68)$ \\
\hline 1.5 & 50.00 & 150.00 & 10000 & Instrument nozzle is blocked \\
\hline
\end{tabular}


found that when the speed of the peristaltic pump was $700 \mathrm{~mL} \cdot \mathrm{h}^{-1}$, obvious water droplets formed in the spray dryer, indicating that the spray droplets were not completely dry, and the yield was low. When the speed decreased to $600 \mathrm{~mL} \cdot \mathrm{h}^{-1}$, the powder was still slightly wet. As $300 \mathrm{~mL} \cdot \mathrm{h}^{-1}$ is the minimum rotation speed of the instrument, the acceptable range of the peristaltic pump speed was thus determined to be between 300 and $500 \mathrm{~mL} \cdot \mathrm{h}^{-1}$.

According to the preparation method in Preparation of Salvianolic Acid Microcapsules, a series of microcapsules was prepared at inlet air temperatures of $150^{\circ} \mathrm{C}, 160^{\circ} \mathrm{C}, 170^{\circ}$ $\mathrm{C}, 180^{\circ} \mathrm{C}, 190^{\circ} \mathrm{C}$, and $200^{\circ} \mathrm{C}$. In the course of the experiment, it was found that when the inlet air temperature was below $170^{\circ} \mathrm{C}$, the droplets could not be dried, indicating that the inlet air temperature cannot be lower than $170^{\circ} \mathrm{C}$.

According to the results of single-factor investigation, the main influencing factors are as follows: the drug-tochitosan ratio (A), the mass concentration of chitosan (B), the speed of the peristaltic pump (C), and the air inlet temperature (D). In order to optimize the prescription and process for preparing microcapsules, an orthogonal test was carried out. The trial protocol is presented in Table 3. Drug loading and yield were taken as the comprehensive evaluation indexes. The weight coeff ton were all 0.5. The results are presented in Tables 3 an 4.

According to the range analysis, the influencing factor for the salvianolic was as follows: $\mathrm{C}>\mathrm{D}>\mathrm{B}>\mathrm{A}$. The

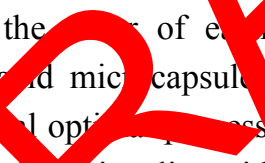
and prescription for the prepar on of vianolic acid microcapsules are $\mathrm{A}_{3} \mathrm{~B}_{3} \mathrm{C}_{3}$, ie, salvio lic acidto-chitosan ratio $=1: 3$, mass conc tration of chitosan $=$ $1.5 \%$, peristaltic pum temperature $=190$

\section{Proof $\mathrm{T}$ ot}

The o mal $\mathrm{p}^{r}$ cess and prescription conditions were obtained basis or the orthogonal test results. Three batches of sa nnolic acid microcapsules were prepared. The results, presentea m Table 5, show that the process has good

Table 3 The Influencing Factors and Levels

\begin{tabular}{|l|c|c|c|c|}
\hline \multirow{2}{*}{ Levels } & \multicolumn{4}{|c|}{ Influencing Factors } \\
\cline { 2 - 5 } & $\mathbf{A ~ ( \mathbf { g ~ g } ^ { - 1 } )}$ & $\mathbf{B}(\%)$ & $\mathbf{C}\left(\mathbf{m L ~}^{-1}\right)$ & $\mathbf{D}\left({ }^{\circ} \mathbf{C}\right)$ \\
\hline 1 & $1.0: 2.0$ & 0.8 & 300 & 170 \\
2 & $1.0: 2.5$ & 1.2 & 400 & 180 \\
3 & $1.0: 3.0$ & 1.5 & 500 & 190 \\
\hline
\end{tabular}

Table 4 The Results of the Orthogonal Test $(n=3)$

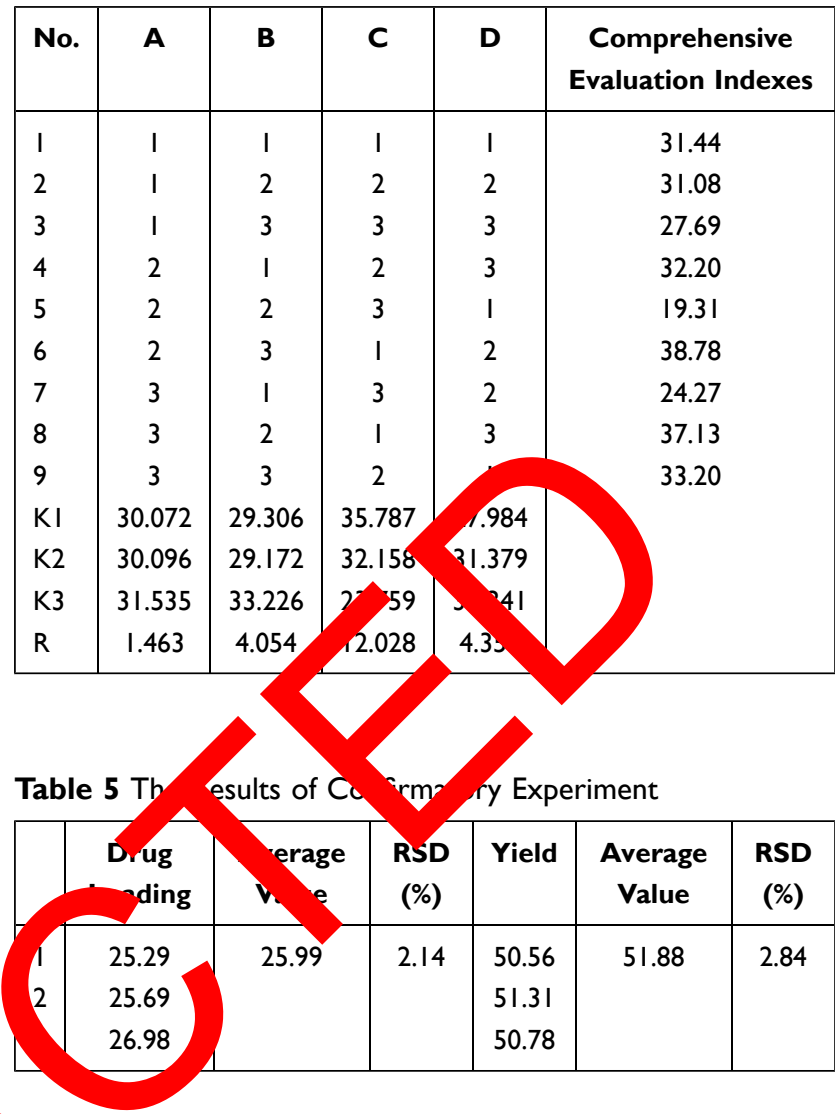

repurucibility. Although the results for the microcapsules prepared according to the optimal process and prescription conditions $\left(\mathrm{A}_{3} \mathrm{~B}_{3} \mathrm{C}_{1} \mathrm{D}_{3}\right)$ were close to the results for orthogonal test $6\left(\mathrm{~A}_{2} \mathrm{~B}_{3} \mathrm{C}_{1} \mathrm{D}_{2}\right)$, in view of the higher proportion of the capsule, and the notion that the higher the rate of encapsulation, the higher the inlet temperature, and the less likely the nozzle is to block, the optimal process and prescription conditions $A_{3} B_{3} C_{1} D_{3}$ were finally selected for the preparation of the microcapsules.

\section{Quality Evaluation Morphology of the Microcapsules}

The microcapsule sample is a slightly yellow powder, with no bad smell, and good dispersibility and stability. The surface morphology of the microcapsules was observed by scanning electron microscope (SEM) (Figure 2). The results indicate that the microcapsule was round, with a smooth and clean surface, and did not adhere.

\section{Particle Diameter}

An appropriate number of salvianolic acid microcapsules were taken and diluted with water. The particle size and zeta potential were determined using a Zetasizer laser particle analyzer, as illustrated in Figure 3. As shown in 


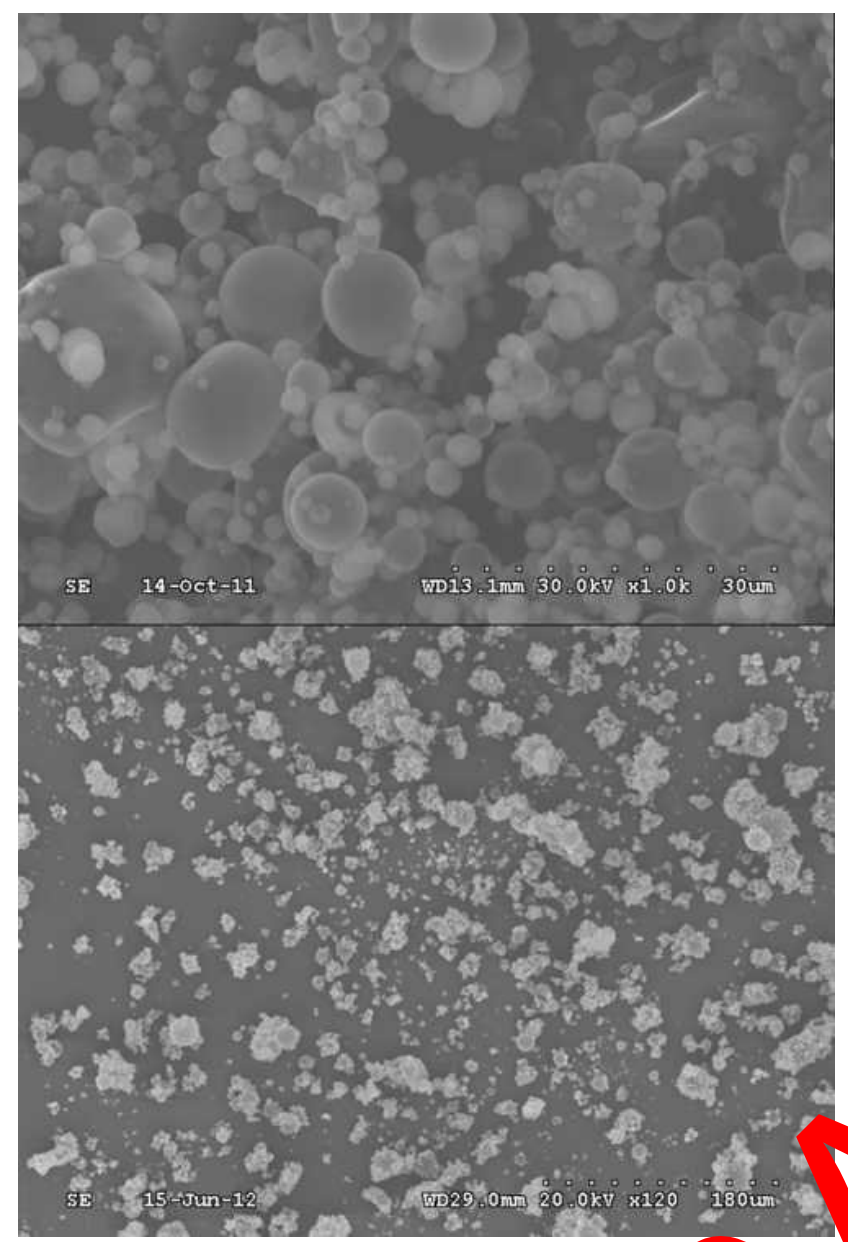

the figure, the average particle size of the microcapsules was $105.63 \pm 2.56 \mathrm{~nm}$, the polydispersity index was 0.411 \pm 0.023 , and the zeta potential was $47.71 \pm 1.36 \mathrm{mv}$. The results indicate that the particle size of the microcapsule was small and the system was stable, but the particle size distribution was not sufficiently uniform; this needs to be improved.

\section{Differential Scanning Calorimetry (DSC)}

The salvianolic acid microcapsules, salvianolic acid extract, chitosan, and physical mixture were determined by DSC. The weight of the sam was roximately $6 \mathrm{mg}$. The test temperature wa ${ }^{\circ} \mathrm{C}$ to 450 and the temperature rose by $10^{\circ} \mathrm{C} \mathrm{m}^{-1}$ (th results ar shown in Figure 4). These results now that sa ian acid and salvianolic acid embo ed in crosphers have similar absorption peaks $25 \quad{ }^{\circ} \mathrm{C}$ an $r^{\prime} 241.53^{\circ} \mathrm{C}$, respectively; there no signit $\mathrm{nt}$ iference between the two groups the ylts indicare that the microcapsules did not olnenge the pro, ties of salvianolic acid.

$\operatorname{Pr}$ iminary tudy on the Release Pro, Mities Microcapsules in vitro Methodunonal Study on Dissolution in vitro $\mathrm{Tr}$ re rate was determined using the $\mathrm{XD}$ release nethod in Appendix II of the Chinese Pharmacopoeia

Figure 2 Microcapsule scanning electron microscope. 015. In the pilot experiment, the optimal release medium

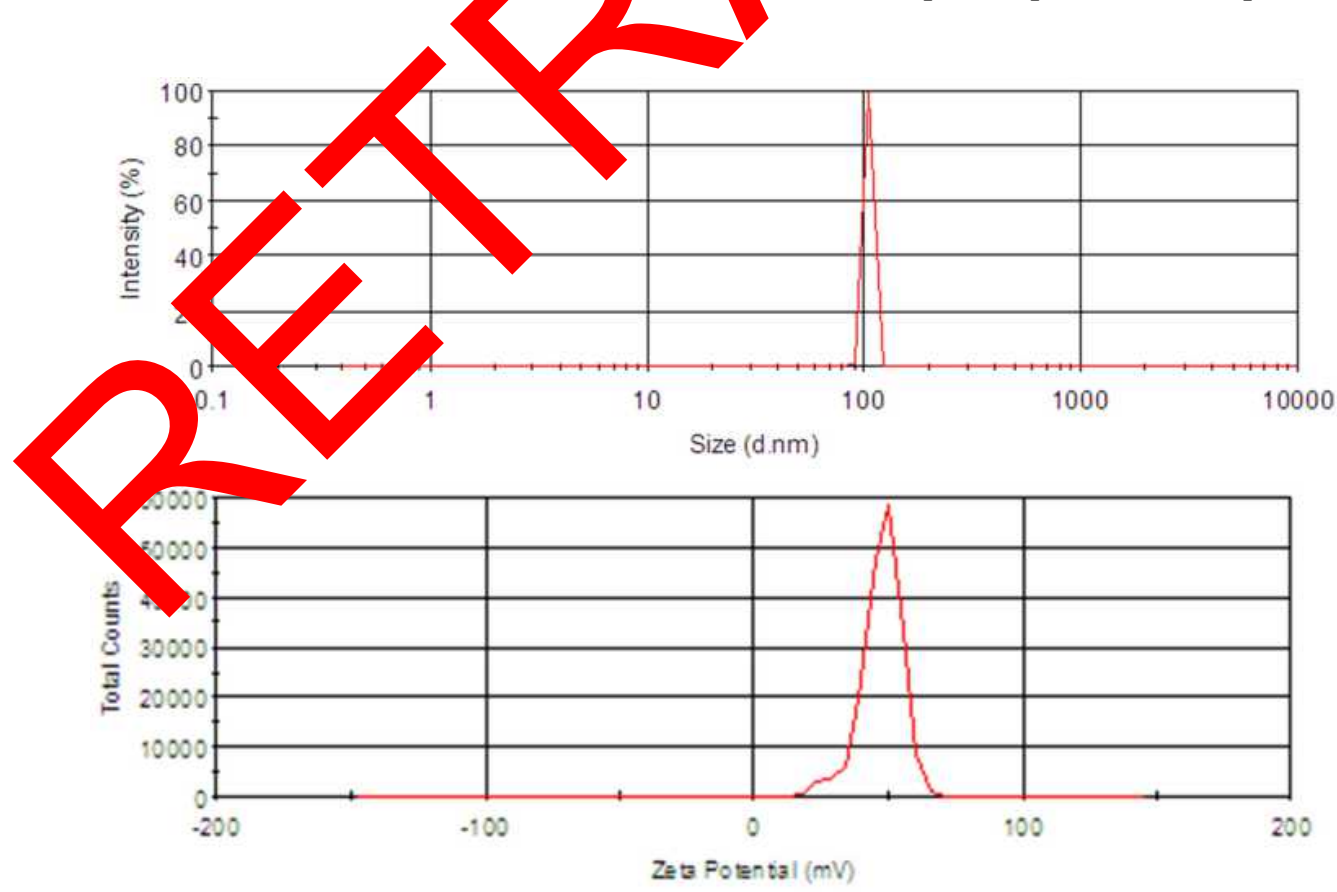

Figure 3 Particle size distribution map and potential diagram. 

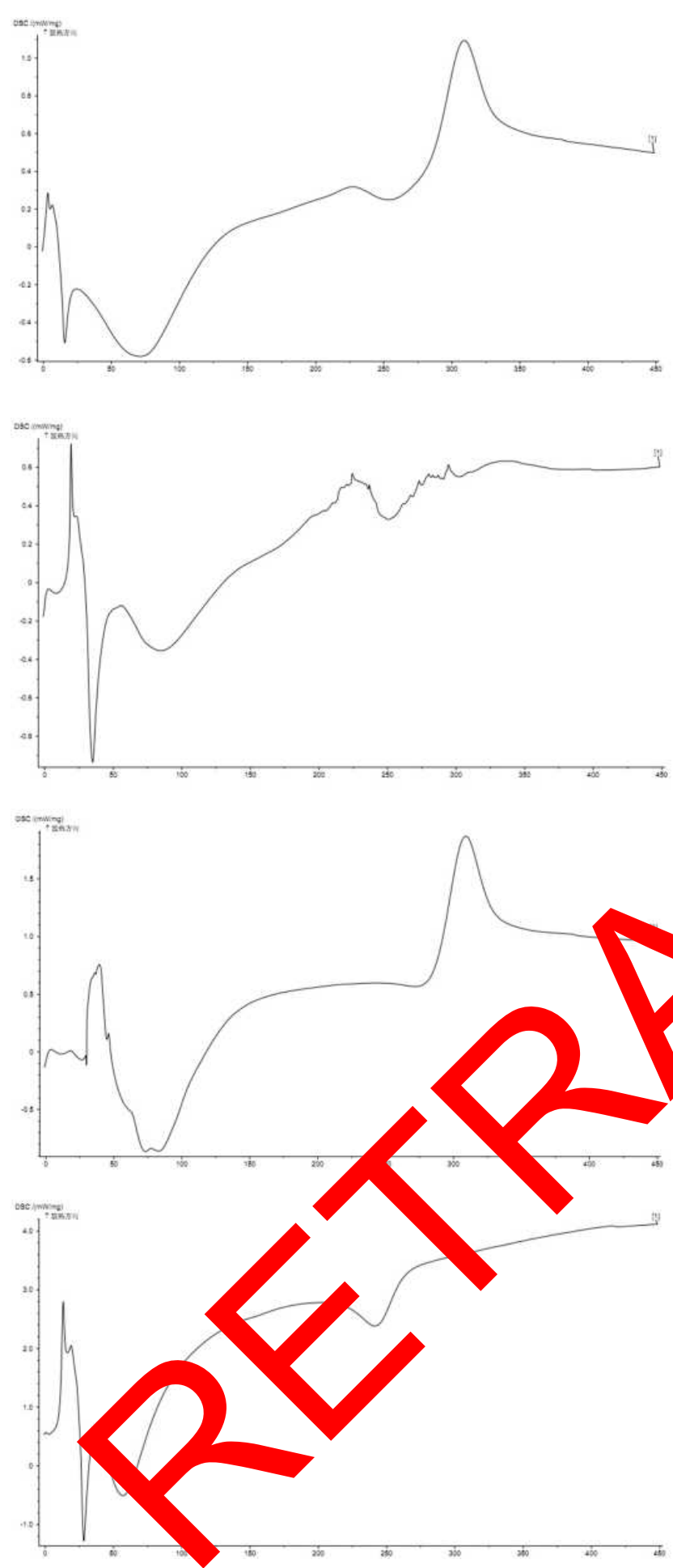

Figure 4 Differential thermal scanning diagram. (A) Physical mixture of salvianolic acid extract and chitosan; (B) salvianolic acid extract; (C) chitosan; (D) microcapsule.

was selected. Water, $0.01 \mathrm{~mol} \cdot \mathrm{L}^{-1}$ hydrochloric acid, phosphate buffer solution $\mathrm{pH} 6.8$, phosphate buffer solution $\mathrm{pH}$ 7.4 , and phosphate buffer solution $\mathrm{pH} 4.5$ were each used to determine the cumulative release degree. The presence of white turbidity was observed in the dissolution cup for the microcapsules in water, phosphate buffer solution $\mathrm{pH} 6.8$, and phosphate buffer $\mathrm{pH} 7.4$, possibly due to the insolubility of the chitosan. ${ }^{8-10}$ In addition, the microcapsule release was too fast in $0.01 \mathrm{moL} \cdot \mathrm{L}^{-1}$ hydrochloric acid, and the salvianolic acid was unstable under these conditions. ${ }^{11-14}$ Therefore, the optimal release medium for the microcapsules was identified as phosphate buffer $\mathrm{pH} 4.5$.

\section{Preparation of Release Medium}

For the acetic acid-sodium a cate bu or solution $(\mathrm{pH}$ 4.5), $18 \mathrm{~g}$ of sodium acetat vas taken, $\mathrm{mL}$ of acetic acid was added, and is w diluted ith water to $1,000 \mathrm{~mL}$ to obtain $\mathrm{t}^{\prime}$ final prodi

\section{Preparation o a S a d Cury}

Next, 2.25 of salvia ic ac B control was accurately weighed and ssolved w $75 \%$ methanol solution to a constant volu of $25 \mathrm{~mL}$, in order to prepare volution of $63.60 \mathrm{~mL} \mathrm{~mL}^{-1}$. Each $0.1,0.2,0.40 .8,1.60$, nd $3.2 \mathrm{~mL}$ solution was taken into a $10-\mathrm{mL}$ volumetric ask, and a \% methanol solution was used to maintain a stant sume. The above series of standard solutions was filtered using a $0.45-\mu \mathrm{m}$ Millipore filter. This was testur based on chromatographic conditions in Sample Specificity Chromatogram. The sample injection was 20 $\mu \mathrm{L}$. Peak area A was measured as the longitudinal coordinate, and linear regression was conducted for the concentration according to the regression equation: $\mathrm{A}=2.1570$ $\mathrm{X}-0.1854, \mathrm{r}^{2}=0.999 .5$. The results reveal that salvianolic acid $\mathrm{B}$ has a good linear relationship between 1.02 and $32.64 \mu \mathrm{g} \cdot \mathrm{mL}^{-1}$.

\section{Determination of Sample Release in vitro}

According to the Second Method "Device" of General Rule 0931 of the Pharmacopoeia of the People's Republic of China $2015,900 \mathrm{~mL}$ of each of the above five release media was used as the release medium, at a temperature of $37.0^{\circ} \mathrm{C} \pm 0.5^{\circ}$ $\mathrm{C}$ and a rotating speed of $100 \mathrm{r} \cdot \mathrm{min}^{-1}$. Each $20 \mathrm{mg}$ of prepared salvianolic acid powder and microcapsule was precisely weighed and placed in a large cup. The sampling times were $30,60,120,180$, and 240 minutes, and the sampling quantity was $5 \mathrm{~mL}$. The initial filter was discarded, and the sample was injected (the same amount of isothermal medium was added at the same time). The release degree was calculated according to the standard curve. The cumulative release curve was plotted (Figure 5), and drug release curve fitting was carried out. The 


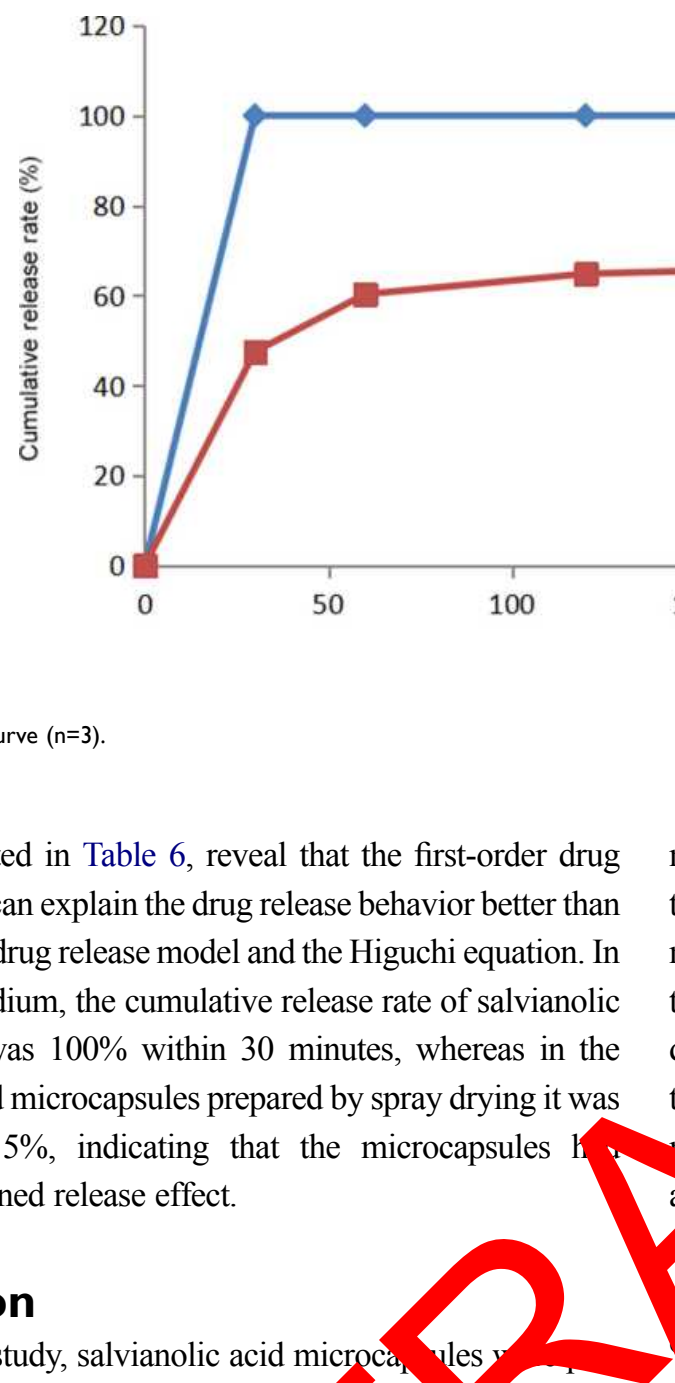

results, presented in Table 6, reveal that the first-order drug release model can explain the drug release behavior better than the zero-order drug release model and the Higuchi equation. In the release medium, the cumulative release rate of salvianolic acid powder was $100 \%$ within 30 minutes, whereas in the salvianolic acid microcapsules prepared by spray drying it was $74.62 \% \pm 3.15 \%$, indicating that the microcapsules a certain sustained release effect.

mainly due to ${ }^{1}$ id dissolut nicrocrystals attached to the surface or the $\mathrm{m}$. ocapsule. Additionally, there may be microp the surfao $f$ the microcapsule, through which the rease medium can quickly enter the microcapsule and diss ve the drug form a higher or even saturated concentratio Accordin to the concentration difference, the drug molecules rapidly diffused from the micropores to create as release. The release was relatively slow within 30 to 40 minutes due to the water absorption and swelling of hitosan, and the micropore diameter was reduced or even sappeared. ${ }^{15-17}$ When the micropore channel was closed, subsequent drug release could only take place slowly by diffusion through the skeleton, or through the degradation of chitosan. ${ }^{18-20}$ After 240 minutes, the cumulative release rate decreased, possibly due to the instability and accelerated degradation of salvianolic acid. However, release conditions in vitro are quite different from those in vivo; further in vivo experiments are therefore necessary.

Limitations remain in the present study. First, this study concerned an in vitro experiment. Due to the great difference between in vitro and in vivo conditions, the findings need to be further confirmed through in vivo experiments. Second, although it is known that salvianolic acid B is one of the effective components of S. miltiorrhiza, its specific mechanism remains unclear, and should be further investigated.

\section{Conclusions}

The results of this study show that sustained-release microcapsules of salvianolic acid can be successfully prepared using marine polysaccharide as the carrier. However, due to the great 
difference between in vitro and in vivo conditions, this needs to be further confirmed through in vivo experiments.

\section{Disclosure}

The authors declare no conflict of interest in this work.

\section{References}

1. Wang L, Ma R, Liu C, et al. Salvia miltiorrhiza: a potential red light to the development of cardiovascular diseases. Curr Pharm Des. 2017;23:1077-1097. doi:10.2174/1381612822666161010105242

2. Yin ZK, Feng ZM, Jiang JS, Zhang X, Zhang PC, Yang YN. Two new tanshinone derivatives from the rhizomes of Salvia miltiorrhiza and their antiviral activities. $J$ Asian Nat Prod Res. 2019;1:1-6.

3. Liang WY, Chen WJ, Yang GH, et al. [Research progress on salvianolic acids of Salvia miltiorrhiza]. Zhongguo Zhong Yao Za Zhi. 2016;41:806-812. Chinese. doi:10.4268/cjcmm20160508

4. Chen W, Chen G. Danshen (Salvia miltiorrhiza Bunge): a prospective healing sage for cardiovascular diseases. Curr Pharm Des. 2017;23:5125-5135. doi:10.2174/1381612823666170822101112

5. Chen F, Li L, Tian DD. Salvia miltiorrhiza roots against cardiovascular disease: consideration of herb-drug interactions. Biomed Res Int. 2017;2017:9868694.

6. Zhou X, Cheung CM, Yang JM, Or PM, Lee WY, Yeung JH. Danshen (Salvia miltiorrhiza) water extract inhibits paracetamol-induced toxicity in primary rat hepatocytes via reducing CYP2E1 activity and oxidative stress. J Pharm Pharmacol. 2015;67:980-989. doi:10.1111/ jphp. 12381

7. Zhou X, Kang X, Tang L, et al. [Pharmaceutical rese of Ligusticum chuanxiong oil microcapsule analgesic gel pe D-optimal mixture design]. Chin Tradit Herb 2019;50:5455-5461. Chinese.

8. Younes I, Rinaudo M. Chitin and chitosan prer ation Structure, properties and app cions. I $r$ Drus 2015;13:1133-1174. doi:10.3390/md130311.

9. Sanina N. Vaccine adjuvants deriy fron the organistns. Biomolecules. 2019;9(8):pii: E340. 10.3390/bio 9080340

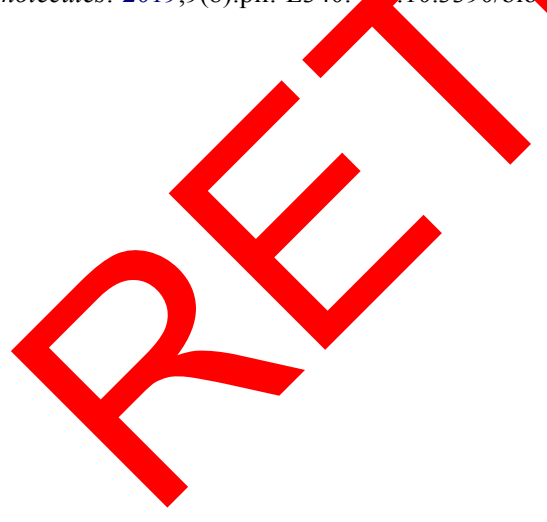

Drug Design, Development and Therapy

Dovepress

\section{Publish your work in this journal}

Drug Design, Development and Therapy is an international, peerreviewed open-access journal that spans the spectrum of drug design and development through to clinical applications. Clinical outcomes, patient safety, and programs for the development and effective, safe, and sustained use of medicines are a feature of the journal, which has also
10. Garg U, Chauhan S, Nagaich U, Jain N. Current advances in chitosan nanoparticles based drug delivery and targeting. Adv Pharm Bull. 2019;9:195-204. doi:10.15171/apb.2019.023

11. Lu ZZ, Zhu JB, Liu TC. [Influence of $\mathrm{pH}$ and additives on stability of salvianolic acid B]. J Dalian Polytech U. 2008;27:209-211. Chinese.

12. Ren ZH, Su HX, Bai YL. [Study on the integration technique for extracting liposoluble and water-soluble components of salvia miltiorrniza]. Chin J Inform Tradit Chin Med. 2009;16:54-56. Chinese.

13. Zhang WX, Xuan L, Ni J. [Stability of salvianolic acid B in water solution]. J Beijing U Tradit Chin Med. 2009;32:856-858. Chinese.

14. Wang B, Zhu WJ, Zeng XL, Fan MW. [Stability of salvianolic acid B in Danshen freeze-dried product injection]. Chin Tradit Pat Med. 2007;29:1479-1482. Chinese.

15. Li S, Hou XP. [Studies on the mation mechanism of alginate-chitosan microcapsule and drug-to $\mathrm{ng}$ and release properties on macromolecular ug]. Acta harmaceut Sin. 2003;38:380-383. Chinese.

16. Nguyen NT, Nguyen LV Can NM t al. The ect of oxidation degree and volume ra of componen on $\mathrm{p}^{\mathrm{r}}$ erties and applications of in situ cro anking b Cogels b on chitosan and hyaluronic acid. Maten Eno Mater Biol Appl. 2019;103:109670. doi:10.1016/i ec. 20 , 49

17. Schmitz $C$ uza LG, Ko idze D asche S, Fischer R, Bortesi L. Conver hitin to defin cosan oligomers: current status and future prospeo Mar Drugs. 2019;17(8):pii: E452. doi:10.3390/ md17080452

Nudri H, Dahma Addaou A, Laajeb A, Lahsini A. Rapid and efficient extraction of chitin and chitosan for scale-up production: effect of pr ess parameters on deacetylation degree and molecular weight. Int Biol Macromol. 2019;139:1092-1102. doi:10.1016/j.

19. $\mathrm{U}$ Y, Ouyang XK, et al. Fabrication of chitosan-based MCS/ZnO@Alg gel microspheres for efficient adsorption of $\mathrm{As}(\mathrm{V})$. J Biol Macromol. 2019;139:886-895. doi:10.1016/j. ijbiomac.2019.08.070

20. Luo Z, Chen H, Wu S, Yang C, Cheng J. Enhanced removal of bisphenol A from aqueous solution by aluminum-based MOF/sodium alginate-chitosan composite beads. Chemosphere. 2019;237:124493. doi:10.1016/j.chemosphere.2019.124493 ibiomac. $2^{f}$. 08.079 been accepted for indexing on PubMed Central. The manuscript management system is completely online and includes a very quick and fair peer-review system, which is all easy to use. Visit http://www. dovepress.com/testimonials.php to read real quotes from published authors. 